\title{
Experimental Research on the Effect of Initial Temperature Coupled with Ignition Energy on the Gas-air Mixture Explosive Limits
}

\author{
Yansong Zhang \\ College of Mining and Safety \\ Engineering \\ Shandong University of Science and \\ Technology \\ Qingdao, Shandong, China \\ zys6407@163.com \\ Wenzhou Du \\ College of Mining and Safety \\ Engineering \\ Shandong University of Science and \\ Technology \\ Qingdao, Shandong, China \\ duwenzhou-01@163.com
}

\author{
Xiangbao Meng* \\ College of Mining and Safety \\ Engineering \\ Shandong University of Science and \\ Technology \\ Qingdao, Shandong, China \\ mxb0538@126.com \\ Jie Zhang \\ College of Mining and Safety \\ Engineering \\ Shandong University of Science and \\ Technology \\ Qingdao, Shandong, China \\ zhangjieskd@126.com
}

\author{
Bo Liu* \\ College of Mining and Safety \\ Engineering \\ Shandong University of Science and \\ Technology \\ Qingdao, Shandong, China \\ skdliubo@126.com
}

\begin{abstract}
In order to study the effect of different initial conditions on gas explosive limits, the gas explosive limits have been measured under different initial temperatures $\left(50 \sim 200^{\circ} \mathrm{C}\right)$ coupled with different ignition energies $(50 \sim 800 \mathrm{~J})$. Besides, it has been obtained that the change rules of the upper and lower limits of gas explosion under the effect of initial temperature, ignition energy and the coupling conditions of the both. The experimental results show that the coupling condition of initial temperature and ignition energy has a great influence on the gas explosive limits. With the increase of initial temperature and ignition energy, the upper limit of gas explosion increases while the lower explosive limit decreases, and both its rising and falling trends tend to be gentle. In addition, according to the analysis on two-factor multi-level variance analysis, it can be seen that both ignition energy and initial temperature have a significant effect on the upper and lower limits of gas explosion under the coupling conditions.
\end{abstract}

Keywords-explosive limits, ignition energy, initial temperature, coupling

\section{INTRODUCTION}

As a major component of coal mine gas, methane is closely related to coal mine safety production [1]. According to statistics, since the founding of the People's Republic of China, there have been 26 coal mine accidents involving more than 100 deaths, 22 of which were caused by coal mine gas explosion [2] resulting in heavy casualties and losses. The causes of heavy casualties caused by gas explosion in coal mine are not only factors such as poor quality of personnel and imperfect management [3] but also insufficient understanding of the limits of coal mine gas explosion [4,5]. Therefore, study on gas explosive limiting system is of great significance to prevent heavy gas explosive accidents in coal mine [6].
There are many factors that affect the gas explosive limits, the main researches of which focus on initial temperature [712], initial pressure [13,14], ignition energy [15], humidity [16], mixing of explosive gas [17,18], mixing of inert gas [19-22], oxygen Content [23], mixing of dust [24-27], water mist [28] and so on.

The methods of prediction and calculation for gas explosive limits include stoichiometric concentration calculation method [29-33], calculation method based on carbon atom atomicity, empirical formula method, and calculation method based on thermodynamic negative entropy and so on. Some scholars have also studied the upper explosive limit $[33,34]$ of low alkanes and olefins under high-temperature and high-pressure conditions. All these studies have made important contributions to the deep understanding of the gas explosive limits.

\section{EXPERIMENTAL EQUIPMENT AND SYSTEM}

Experiment on influence of initial temperature coupled with ignition energy on the gas explosive limit has been conducted in a test equipment for gas explosive characteristics in special environment. The equipment is shown in Figure 1. Its main part is an explosive tank with a volume of $20 \mathrm{~L}$ and the explosive tank contains an interlayer in which the high temperature heat -conducting oil and the built-in electric furnace wire are relied on to heat the mixed gas inside the tank to assure that the mixed gas is in the ambient temperature required by the test before explosion. The temperature range of the test plant can be set at $10{ }^{\circ} \mathrm{C} \sim 200{ }^{\circ} \mathrm{C}$, which can meet the requirement on the initial temperature of $50^{\circ} \mathrm{C} \sim 200^{\circ} \mathrm{C}$ in this test. 
The high energy ignition energy generator (shown in Fig.2) which provides ignition energy for the test has a wide energy range and continuously adjustable energy values. The range of the ignition energy is $0.1 \mathrm{~mJ} \sim 1000 \mathrm{~J}$, which can meet the requirement of ignition energy $50 \mathrm{~J} \sim 800 \mathrm{~J}$ in this test.

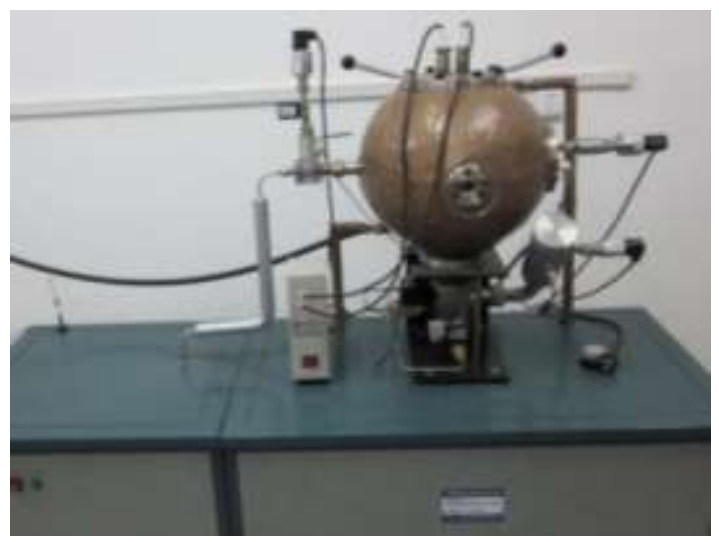

Fig. 1. Test equipment for gas explosive

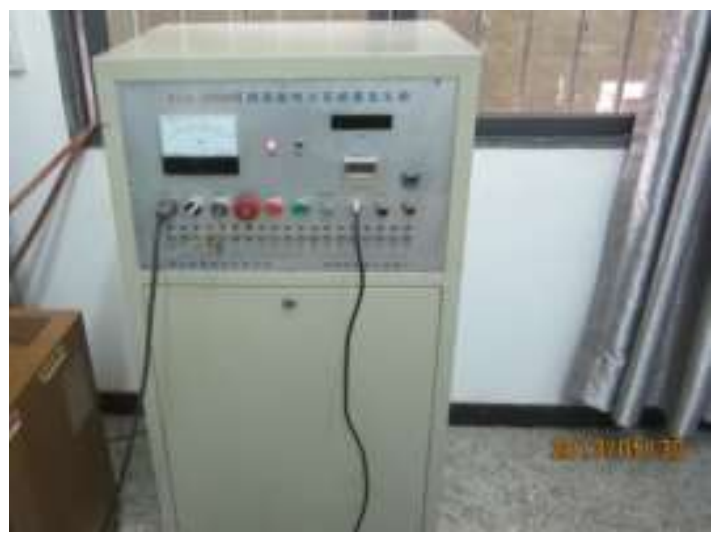

Fig. 2. High energy ignition energy generator characteristics in special environment

As shown in Figure 3, the test system consists of gas distribution system, high energy spark ignition system, vacuum pumping system, data acquisition system, control system, post-processing system, explosive tank and so on. The control system uses sequential circuits to control the gas distribution system and high energy spark ignition system. At the same time, the explosive tank and control system are connected to the data acquisition system through the wireless monitoring transmitter, and the postprocessing system directly processes the data gathered by data acquisition system. The entire system is a digital controlled, visualized, high integrated and automatic acquired device, and the whole experimental operation process is more accurate, convenient and safe.

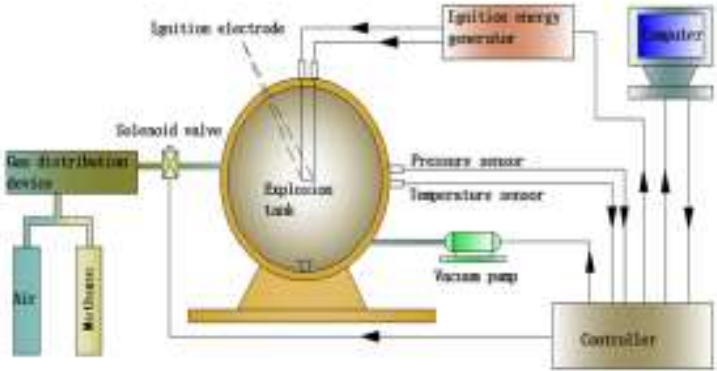

Fig. 3. Technical schematic diagram of experimental system

\section{EXPERIMENTAL SCHEME}

\section{A. Experimental Content}

The test has carried out to messure the explosive limits of gas-air mixture under different coupling conditions between different initial temperatures and ignition energies. The test levels of initial temperature and ignition energy are selected as follows:

Test level of initial temperature: $50{ }^{\circ} \mathrm{C}, 100^{\circ} \mathrm{C}, 150{ }^{\circ} \mathrm{C}$, $200^{\circ} \mathrm{C}$;

Test level of ignition energy: 50J, 100J, 400J, 800J.

In order to shorten the test waiting time, a special temperature is coupled with the different ignition energies one by one in test due to the features of test equipment for gas explosive characteristics in special environment, such as the difficulty in temperature rise and good heat preservation effect. Firstly, the test measures the upper explosive limit in an ambient temperature of $50^{\circ} \mathrm{C}$ coupled with the ignition energy of $50 \mathrm{~J}, 100 \mathrm{~J}, 400 \mathrm{~J}$ or $800 \mathrm{~J}$, separately. By analogy, different upper explosive limits have been tested under the conditions of ambient temperature of $100^{\circ} \mathrm{C}, 150^{\circ} \mathrm{C}$, $200^{\circ} \mathrm{C}$ coupled with different ignition energy, separately.

In the same way, the different lower explosive limits of gas have been tested under conditions of different temperatures coupled with different ignition energies.

\section{B. Procedure}

(1) Calibrate the sensor before the test and connect the pressure, temperature sensor and other auxiliary equipment with the explosive tank as a whole. Besides, all valves should be closed before the test;

(2) Connect the data acquisition system to the computer, turn it on and calibrate it;

(3) Compound the needed specific concentration of gas-air mixture according to the airbag distribution method;

(4) Turn on the high energy ignition energy generator and adjust the ignition energy to the desired gear;

(5) Turn on the vacuum pump to evacuate the tank;

(6) Inject the configured gas-air mixture into the explosion tank;

(7) Use infrared methane sensors to monitor the gas concentration in the tank, and use the data acquisition 
system to monitor the initial pressure, initial temperature and other parameters in explosion vessel;

(8) Turn on the heating system to heat the tank until reach the test set temperature;

\section{(9) Ignition;}

(10) Save the test data, then open the canister bleed valve and turn on the vacuum pump to ventilate and prepare for the next test.

\section{EXPERIMENTAL RESULTS AND ANALYSIS}

\section{A. Test results}

The upper and lower limits of gas explosion on initial temperature coupled with ignition energy are shown in Table 1 and Table 2:

TABLE I. THE UPPER LIMIT OF GAS EXPLOSION ON INITIAL TEMPERATURES COUPLED WITH IGNITION ENERGY (\%)

\begin{tabular}{lllll}
\hline & $50 J$ & $100 J$ & $400 J$ & $800 J$ \\
\hline $50{ }^{\circ} \mathrm{C}$ & 16.3 & 16.5 & 17.0 & 17.1 \\
$100^{\circ} \mathrm{C}$ & 16.8 & 17.0 & 17.5 & 17.6 \\
$150^{\circ} \mathrm{C}$ & 17.2 & 17.4 & 18.0 & 18.1 \\
$200^{\circ} \mathrm{C}$ & 17.5 & 17.7 & 18.3 & 18.4 \\
\hline
\end{tabular}

TABLE II. THE LOWER LIMIT OF GAS EXPLOSION ON INITIAL TEMPERATURES COUPLED WITH IGNITION ENERGY (\%)

\begin{tabular}{lllll}
\hline & $50 \mathrm{~J}$ & $100 \mathrm{~J}$ & $400 \mathrm{~J}$ & $800 \mathrm{~J}$ \\
\hline $50^{\circ} \mathrm{C}$ & 4.90 & 4.81 & 4.65 & 4.59 \\
$100^{\circ} \mathrm{C}$ & 4.61 & 4.51 & 4.37 & 4.33 \\
$150^{\circ} \mathrm{C}$ & 4.42 & 4.32 & 4.20 & 4.17 \\
$200^{\circ} \mathrm{C}$ & 4.25 & 4.17 & 4.06 & 4.02 \\
\hline
\end{tabular}

\section{B. Impact analysis of initial temperature on gas explosive} limits

To explore the rules of gas explosive limits as a function of initial temperature variation, the test results in Table 1 and Table 2 are plotted in the coordinate system with the initial temperature as abscissa and the gas explosive limiting concentration as the ordinate, and data fitting is performed. So, the fitting curves of the upper and lower explosive limits varied with different initial temperatures are shown in Figure 4 and Figure 5, respectively.

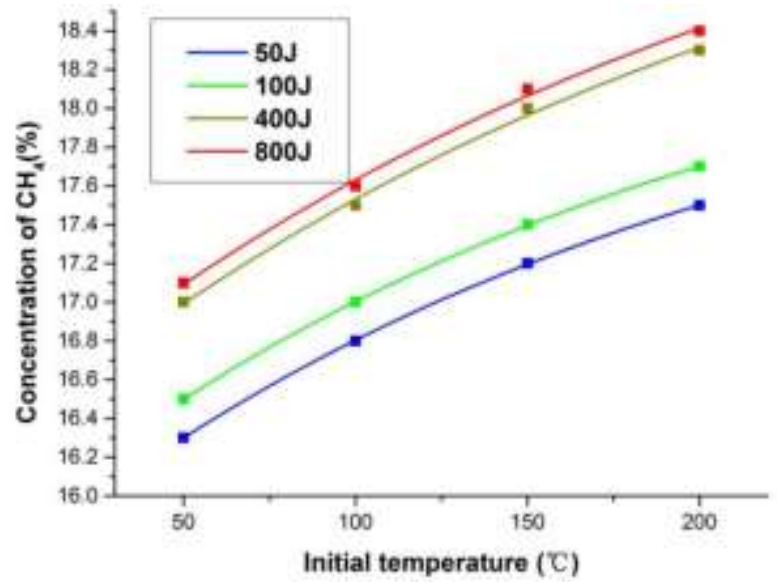

Fig. 4. Fitting curve of upper limit of gas explosion on different initial temperature

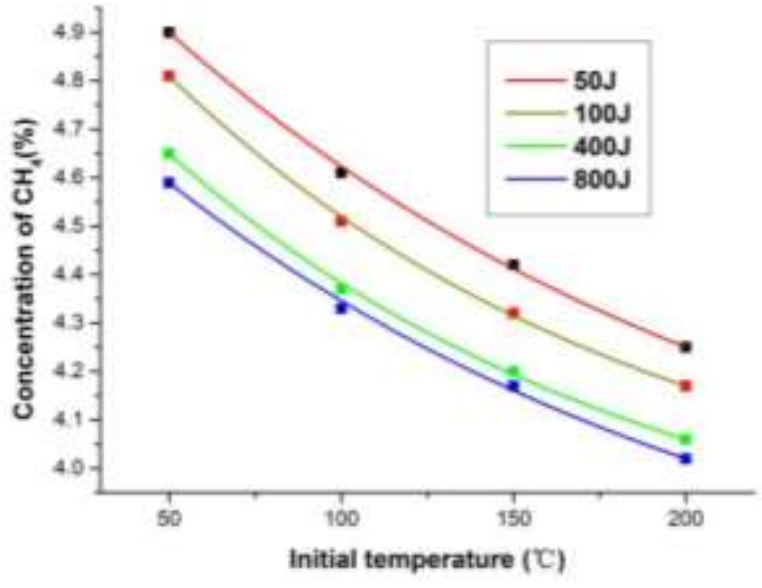

Fig. 5. Fitting curve of lower limit of gas explosion on different initial temperature

As can be seen from Figure 4, with the initial temperature gradually increased, the upper limit of gas explosion gradually increases too, but its upward trend gradually slows down. For example, the upper limiting change rates of gas explosion are $0.01 \% /{ }^{\circ} \mathrm{C}$ and $0.006 \% /{ }^{\circ} \mathrm{C}$ when the ignition energy is $50 \mathrm{~J}$ and the initial temperatures are in the range of $50 \sim 100{ }^{\circ} \mathrm{C}$ and $150 \sim 200^{\circ} \mathrm{C}$, respectively. The upper limit of gas explosion has a similar change when the ignition energies are $100 \mathrm{~J}, 400 \mathrm{~J}$ and $800 \mathrm{~J}$ respectively. As can be seen from Figure 5, with the initial temperature gradually increased, the lower limit of gas explosion gradually decreases, but its upward trend gradually slows down. For example, the lower limiting change rates of gas explosion are $0.0058 \% /{ }^{\circ} \mathrm{C}$ and $0.0034 \% /{ }^{\circ} \mathrm{C}$ when the ignition energy is $50 \mathrm{~J}$ and the initial temperatures are within the range of $50 \sim$ $100{ }^{\circ} \mathrm{C}$ and $150 \sim 200^{\circ} \mathrm{C}$, respectively. The lower limit of gas explosion has a similar change when the ignition energies are $50 \mathrm{~J}, 100 \mathrm{~J}$ and $400 \mathrm{~J}$ respectively.

Near the upper and lower limits of gas explosion, the explosion systems are in the states of fuel-rich and oxygenrich, respectively. The increase of initial temperature can increase the probability of effective collision of methane molecules and oxygen molecules to a certain extent and increase the number of activated molecules in those two states, so that when the temperature increases, the upper limit of gas explosion increases while the lower limit of gas explosion decreases. But as the probability of effective collision decreases rapidly due to the enhancement of rich or oxygen-rich condition, the change rates of the upper and lower explosive limits are getting smaller and smaller resulting in the curve shapes in Figure 4 and Figure 5.

The initial temperature is used as an independent variable $x$ and the upper limiting concentration of gas explosion is used as a function $y$, then the curve in Figure 4 is in accordance with the exponential equation shown in equation (1):

$$
y=y_{0}+A_{1} \exp \left(\frac{x}{t_{1}}\right),(50 \leq x \leq 200)
$$

The values of each parameter in equation (1) are shown in Table 3. 
TABLE III. PARAMETER COMPARISON TABLE

\begin{tabular}{ccccc}
\hline $\begin{array}{c}\text { Ignition } \\
\text { energy } / \mathrm{J}\end{array}$ & $\mathrm{y}_{0}$ & $\mathrm{~A}_{1}$ & $\mathrm{t}_{1}$ & $\mathrm{R}_{2}$ \\
\hline 50 & 18.57498 & -2.92387 & -199.58802 & 0.99988 \\
100 & 18.77498 & -2.92387 & -199.58802 & 0.99988 \\
400 & 19.74875 & -3.42817 & -229.68781 & 0.99248 \\
800 & 19.84875 & -3.42817 & -229.68779 & 0.99248 \\
\hline
\end{tabular}

The initial temperature is used as the independent variable $\mathrm{x}$ and the lower limiting concentration of gas explosion is used as a function y, then the curve in Figure 5 is in accordance with the exponential equation shown in Equation (2):

$$
y=y_{0}+A_{1} \exp \left(\frac{-\left(x-x_{0}\right)}{t_{1}}\right),(50 \leq x \leq 200)
$$

The values of each parameter in equation (2) are shown in Table 4

TABLE IV. PARAMETER COMPARISON TABLE

\begin{tabular}{cccccc}
\hline $\begin{array}{c}\text { Ignition } \\
\text { energy /J }\end{array}$ & $\mathrm{y}_{0}$ & $\mathrm{~A}_{1}$ & $\mathrm{x}_{0}$ & $\mathrm{t}_{1}$ & $\mathrm{R}_{2}$ \\
\hline 30 & 3.7207 & 1.1793 & 50 & 187.237 & 0.99952 \\
100 & 3.81997 & 0.99003 & 50 & 144.2695 & 0.99542 \\
400 & 3.73732 & 0.91268 & 50 & 144.2695 & 0.98245 \\
800 & 3.5754 & 1.0146 & 50 & 181.80287 & 0.98578 \\
\hline
\end{tabular}

C. Impact analysis of ignition energy on gas explosive limits

To explore the rules of gas explosive limits as a function of ignition energy variation, the test results in Table 1 and Table 2 are plotted in the coordinate system with the ignition energy as the abscissa and the gas explosive limiting concentration as the ordinate, and data fitting is performed. So, the fitting curves of the upper and lower explosive limits varied with different ignition energies are shown in Figure 6 and Figure 7, respectively.

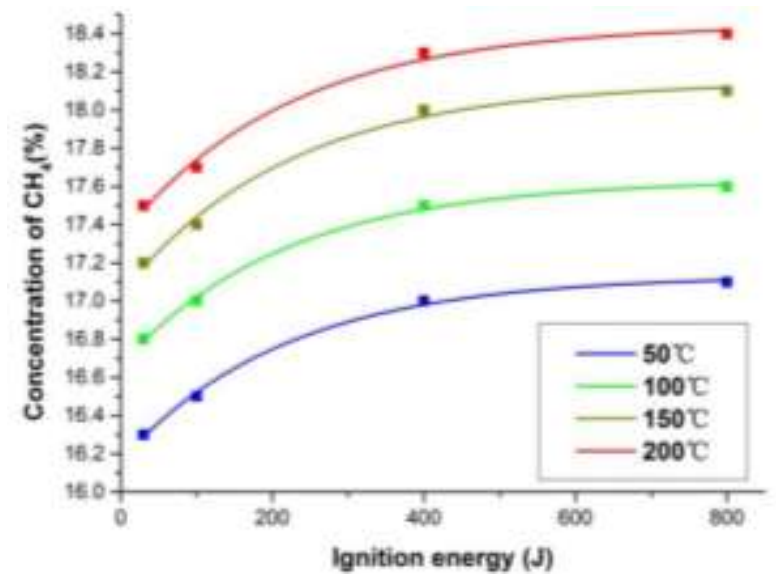

Fig. 6. Fitting curve of upper limit of gas explosion on different ignition energy

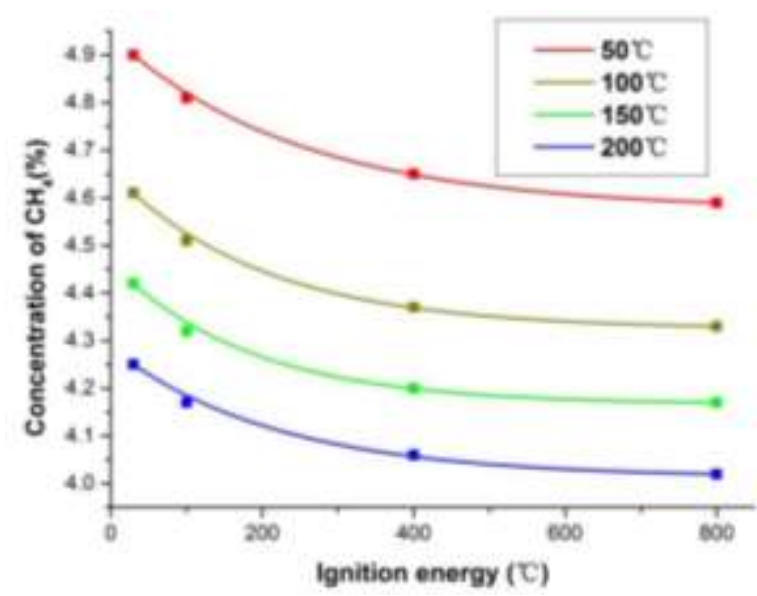

Fig. 7. Fitting curve of lower limit of gas explosion on different ignition energy

The upper limit of gas explosion has a similar change when the ignition energies are $100 \mathrm{~J}, 400 \mathrm{~J}$ and $800 \mathrm{~J}$ respectively. As can be seen from Figure 5, with the initial temperature gradually increased, the lower limit of gas explosion gradually decreases, but its upward trend gradually slows down. For example, the lower limiting change rates of gas explosion are $0.0058 \% /{ }^{\circ} \mathrm{C}$ and $0.0034 \% /{ }^{\circ} \mathrm{C}$ when the ignition energy is $50 \mathrm{~J}$ and the initial temperatures are within the range of $50 \sim 100{ }^{\circ} \mathrm{C}$ and $150 \sim 200^{\circ} \mathrm{C}$, respectively. The lower limit of gas explosion has a similar change when the ignition energies are 50J, $100 \mathrm{~J}$ and $400 \mathrm{~J}$ respectively.

As can be seen from Figure 6, with the ignition energy gradually increased, the upper limit of gas explosion gradually increases too, but its upward trend slows down gradually. For example, the upper limiting change rates of gas explosion are $0.004 \% / \mathrm{J}$ and $0.00025 \% / \mathrm{J}$ when the initial temperature is $50^{\circ} \mathrm{C}$ and the ignition energies are within the range of 50 100J and 400 800J. The lower limit of gas explosion has a similar change when the initial temperatures are $100^{\circ} \mathrm{C}, 150^{\circ} \mathrm{C}$ and $200^{\circ} \mathrm{C}$ respectively. As can be seen from Figure 7 , with the ignition energy gradually increased, the lower limit of gas explosion gradually decreases, but its downward trend slows down gradually. For example, the lower limiting change rates of gas explosion are $0.0058 \% /{ }^{\circ} \mathrm{C}$ and $0.0034 \% /{ }^{\circ} \mathrm{C}$ when the initial temperature is $50^{\circ} \mathrm{C}$ and the ignition energies are within the range of $50 \sim 100 \mathrm{~J}$ and $400 \sim 800 \mathrm{~J}$, respectively. The lower limit of gas explosion has a similar change when the initial temperature are $100^{\circ} \mathrm{C}, 150^{\circ} \mathrm{C}$ and $200^{\circ} \mathrm{C}$ respectively.

Near the upper and lower limits of gas explosion, the explosion systems are in the states of fuel-rich and oxygenrich, respectively. The increase of ignition energy can increase the probability of effective collision of methane molecules and oxygen molecules to a certain extent and increase the number of activated molecules in those two states, so that when the ignition energy increases, the upper limit of gas explosion increases while the lower limit of gas explosion decreases. But as the probability of effective collision decreases rapidly due to the enhancement of rich or oxygen-rich state condition, the change rates of the upper and lower explosive limits are getting smaller and smaller resulting in the curve shapes in Figure 6 and Figure 7.

The ignition energy is used as an independent variable $\mathrm{x}$ and the upper limiting concentration of gas explosion is used 
as a function $y$, then the curve in Figure 6 is in accordance with the exponential equation shown in equation (3):

$$
y=y_{0}+A_{1} \exp \left(\frac{x}{t_{1}}\right) \quad,(50 \leq x \leq 800)
$$

The values of each parameter in equation (3) are shown in Table 5.

TABLE V. PARAMETER COMPARISON TABLE

\begin{tabular}{ccccc}
\hline $\begin{array}{c}\text { Initial } \\
50\end{array}$ & $\mathrm{y}_{0}$ & $\mathrm{~A}_{1}$ & $\mathrm{t}_{1}$ & $\mathrm{R}_{2}$ \\
\hline 100 & 17.13473 & -0.97234 & -217.15127 & 0.99276 \\
150 & 17.63473 & -0.97234 & -217.15127 & 0.99276 \\
18.14889 & -1.11202 & -222.40695 & 0.98129 \\
200 & 18.44889 & -1.11202 & -222.40695 & 0.98129
\end{tabular}

The ignition energy is used as the independent variable $\mathrm{x}$ and the lower limiting concentration of gas explosion is used as a function $\mathrm{y}$, then the curve in Figure7 is in accordance with the exponential equation shown in Equation (4):

$$
y=y_{0}+A_{1} \exp \left(\frac{-\left(x-x_{0}\right)}{t_{1}}\right),(50 \leq x \leq 800)
$$

The values of each parameter in equation (4) are shown in Table 6.

ABLE VI. PARAMETER COMPARISON TABLE

\begin{tabular}{cccccc}
\hline $\begin{array}{c}\text { Initial } \\
\text { (1) }\end{array}$ & $\mathrm{y}_{0}$ & $\mathrm{~A}_{1}$ & $\mathrm{x}_{0}$ & $\mathrm{t}_{1}$ & $\mathrm{R}_{2}$ \\
\hline 50 & 4.57526 & 0.32474 & 30 & 249.01854 & 0.99452 \\
100 & 4.32377 & 0.28623 & 30 & 201.18379 & 0.99442 \\
150 & 4.16635 & 0.25365 & 30 & 181.54412 & 0.98253 \\
200 & 4.01288 & 0.23712 & 30 & 219.61183 & 0.98267 \\
\hline
\end{tabular}

D. Impact analysis of coupling of ignition energy and initial temperature on gas explosive limits

According to equations (4) and (5), the upper and lower explosive limits can be figured out under the condition that the initial temperature of $50^{\circ} \mathrm{C}, 100^{\circ} \mathrm{C}, 150^{\circ} \mathrm{C}$ and $200^{\circ} \mathrm{C}$ are coupled with different ignition energy (50-800J) respectively. The data are shown in Table 7 and Table 8:

TABLE VII. GAS EXPLOSIVE UPPER LIMIT UNDER TEMPERATURE COUPLED WITH IGNITION ENERGY $(\%)$

\begin{tabular}{ccccc}
\hline & $50^{\circ} \mathrm{C}$ & $100^{\circ} \mathrm{C}$ & $150^{\circ} \mathrm{C}$ & $200^{\circ} \mathrm{C}$ \\
\hline $50 \mathrm{~J}$ & 16.288 & 16.788 & 17.177 & 17.477 \\
$100 \mathrm{~J}$ & 16.521 & 17.021 & 17.440 & 17.740 \\
$170 \mathrm{~J}$ & 16.690 & 17.190 & 17.631 & 17.931 \\
$240 \mathrm{~J}$ & 16.813 & 17.313 & 17.771 & 18.071 \\
$310 \mathrm{~J}$ & 16.901 & 17.401 & 17.873 & 18.173 \\
$380 \mathrm{~J}$ & 16.966 & 17.466 & 17.947 & 18.247 \\
\hline
\end{tabular}

\begin{tabular}{lcccc}
\hline & $50^{\circ} \mathrm{C}$ & $100^{\circ} \mathrm{C}$ & $150^{\circ} \mathrm{C}$ & $200^{\circ} \mathrm{C}$ \\
\cline { 1 - 1 } $450 \mathrm{~J}$ & 17.012 & 17.512 & 18.002 & 18.302 \\
$520 \mathrm{~J}$ & 17.046 & 17.546 & 18.042 & 18.342 \\
$590 \mathrm{~J}$ & 17.070 & 17.570 & 18.071 & 18.371 \\
$660 \mathrm{~J}$ & 17.088 & 17.588 & 18.092 & 18.392 \\
$730 \mathrm{~J}$ & 17.101 & 17.601 & 18.107 & 18.407 \\
$800 \mathrm{~J}$ & 17.110 & 17.610 & 18.118 & 18.418 \\
\hline
\end{tabular}

TABLE VIII. GAS EXPLOSIVE LOWER LIMIT UNDER TEMPERATURE COUPLED WITH IGNITION ENERGY $(\%)$

\begin{tabular}{ccccc}
\hline & $50^{\circ} \mathrm{C}$ & $100^{\circ} \mathrm{C}$ & $150^{\circ} \mathrm{C}$ & $200^{\circ} \mathrm{C}$ \\
\hline $50 \mathrm{~J}$ & 4.900 & 4.610 & 4.420 & 4.250 \\
$100 \mathrm{~J}$ & 4.820 & 4.526 & 4.339 & 4.185 \\
$170 \mathrm{~J}$ & 4.760 & 4.466 & 4.284 & 4.138 \\
$240 \mathrm{~J}$ & 4.715 & 4.425 & 4.246 & 4.104 \\
$310 \mathrm{~J}$ & 4.681 & 4.395 & 4.221 & 4.079 \\
$380 \mathrm{~J}$ & 4.655 & 4.374 & 4.203 & 4.061 \\
$450 \mathrm{~J}$ & 4.635 & 4.359 & 4.191 & 4.048 \\
$520 \mathrm{~J}$ & 4.621 & 4.349 & 4.183 & 4.038 \\
$590 \mathrm{~J}$ & 4.610 & 4.341 & 4.178 & 4.031 \\
$660 \mathrm{~J}$ & 4.601 & 4.336 & 4.174 & 4.026 \\
$730 \mathrm{~J}$ & 4.595 & 4.333 & 4.172 & 4.023 \\
$800 \mathrm{~J}$ & 4.590 & 4.330 & 4.170 & 4.020 \\
\hline
\end{tabular}

The data in Table 7 and Table 8 are plotted in a threedimensional Cartesian coordinate system with the initial temperature, ignition energy and methane explosive limit concentration as the coordinate axes, and data fitting is performed. The fitting surfaces of upper and lower explosive limits are shown in Fig. 8 and Fig. 9.

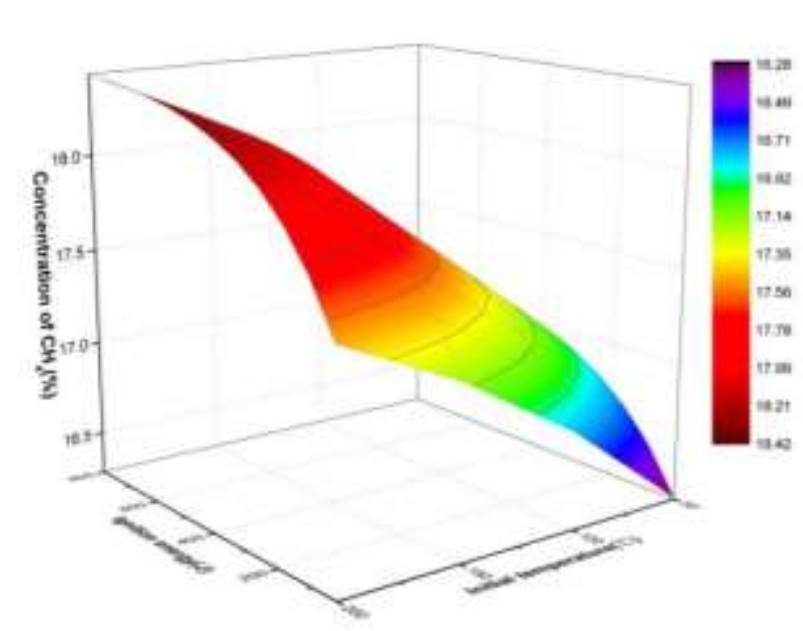

Fig. 8. Surface of gas upper explosive limit on initial temperature coupled with ignition 


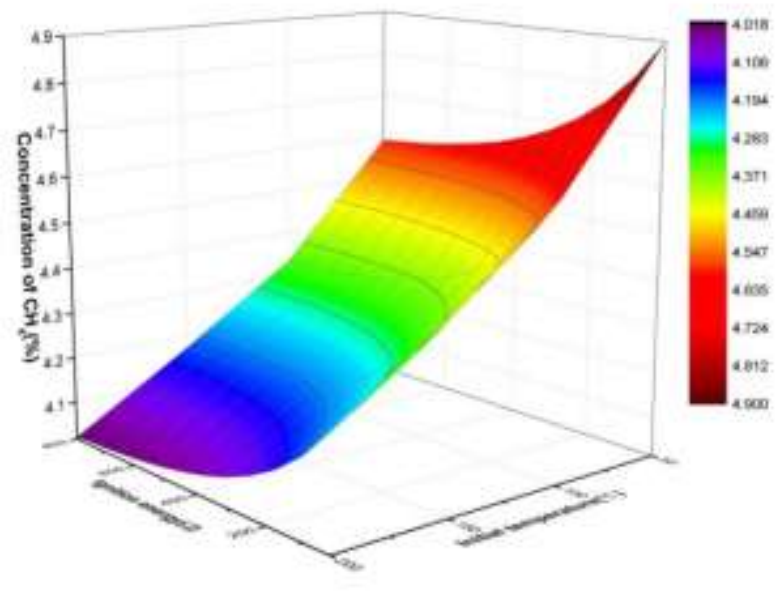

Fig. 9. Surface of gas lower explosive limit on energy initial temperature coupled with ignition energy

Used the initial temperature as the independent variable $\mathrm{x}$, the ignition energy as the independent variable $y$ and the upper concentration of methane explosion as a function $\mathrm{z}$, then the surface in Figure 8 is consistent with the exponential equation shown in equation (5).

$$
\begin{gathered}
z=z_{0}+a x+b y+c x^{2}+d y^{2}+f x y \\
(50 \leq x \leq 200, \quad 50 \leq y \leq 800)
\end{gathered}
$$

The values of each parameter in equation (5) are shown in Table 9.

TABLE IX. PARAMETER OF FITTING FUNCTION COMPARISON TABLE

\begin{tabular}{ccccccc}
\hline $\mathrm{z}_{0}$ & $\mathrm{a}$ & $\mathrm{b}$ & $\mathrm{c}$ & $\mathrm{d}$ & $\mathrm{f}$ & $\mathrm{R}_{2}$ \\
\hline $4.2089 \mathrm{E}$ & 1 & $1.89605 \mathrm{E}$ & $1.40425 \mathrm{E}$ & $1.72656 \mathrm{E}$ & $1.08618 \mathrm{E}$ & \multirow{1}{*}{1} \\
-11 & 1 & -14 & -13 & -19 & -15 & \\
\hline
\end{tabular}

Used the initial temperature as the independent variable $\mathrm{x}$, the ignition energy as the independent variable $y$ and the upper concentration of methane explosion as a function $\mathrm{z}$, then the surface in Figure 9 is consistent with the exponential equation shown in equation (6).

$$
\begin{gathered}
z=z_{0}+a x+b y+c x^{2}+d y^{2}+f x y \\
(50 \leq x \leq 200, \quad 50 \leq y \leq 800)
\end{gathered}
$$

The values of each parameter in equation (6) are shown in Table 10.

TABLE $X$. PARAMETER COMPARISON TABLE

\begin{tabular}{ccccccc}
\hline $\mathrm{z}_{0}$ & $\mathrm{a}$ & $\mathrm{b}$ & $\mathrm{c}$ & $\mathrm{d}$ & $\mathrm{f}$ & $\mathrm{R}_{2}$ \\
\hline $8.34964 \mathrm{E}$ & 1 & $3.07298 \mathrm{E}$ & $3.89129 \mathrm{E}$ & $4.18174 \mathrm{E}$ & $6.7904 \mathrm{E}$ & \multirow{2}{*}{1} \\
-12 & 1 & -15 & -13 & -21 & -16 & \\
\hline
\end{tabular}

As can be seen from Figure 8, with the gradually increased of initial temperature and ignition energy, the upper limit of gas explosion increases gradually. Besides, the upper limit of gas explosive surface is convex and the surface becomes more and more gentle, which indicates the upward trend gradually becomes slower. As can be seen from Figure 9, with the gradually increased of initial temperature and ignition energy, the lower limit of gas explosion decreases gradually. Besides, the lower limit of gas explosive surface is concave and the surface becomes more and more gentle, which indicates the downward trend gradually becomes slower.

The change rule of gas explosive limits on initial temperature coupled with ignition energy is consistent with the change law of gas explosive limits under the influence of the single factor, initial temperature or ignition energy. As shown in Table 7 and Table 8, the limiting range of gas explosion is $14.398 \%$ when the initial temperature is $200^{\circ} \mathrm{C}$ and the ignition energy is $800 \mathrm{~J}$, while its limiting range is $11.388 \%$ when the initial temperature is $50{ }^{\circ} \mathrm{C}$ and the ignition energy is 50J. Compared these two conditions, the former limiting range of gas explosion value is $26.4 \%$ larger than the latter one, which shows the difference on coupling condition of initial temperature and ignition energy has a relatively large impact on the gas explosive limit.

\section{E. Analysis on the two-factor of gas explosive limits}

In order to investigate whether the initial temperature and ignition energy have a significant influence on gas explosive limits, the analysis of two-factor multi-level variance has been performed on the data of gas explosive limits (i.e. the data in Table 1 and Table 2) under different combinations of initial temperature and ignition energy levels. The analyze

\begin{tabular}{|c|c|c|c|c|c|c|}
\hline Resource & SS & $\mathrm{df}$ & MS & $\mathrm{F}$ & $\begin{array}{c}\text { P- } \\
\text { value }\end{array}$ & conclusion \\
\hline $\begin{array}{l}\text { ignition } \\
\text { energy }\end{array}$ & 3.57 & 3 & 1.19 & 1071 & $\begin{array}{c}8.31 \mathrm{E} \\
-12\end{array}$ & $\begin{array}{l}\text { extremely } \\
\text { significant }\end{array}$ \\
\hline $\begin{array}{c}\text { initial } \\
\text { temperature }\end{array}$ & 2.06 & 3 & 0.686667 & 618 & $\begin{array}{c}9.77 \mathrm{E} \\
-11\end{array}$ & $\begin{array}{l}\text { extremely } \\
\text { significant }\end{array}$ \\
\hline error & 0.01 & 9 & 0.001111 & & & \\
\hline total & 5.64 & 15 & & & & \\
\hline
\end{tabular}
results are shown in Table 11 and Table 12.

TABLE XI. TWO-FACTOR VARIANCE ANALYSIS ON EXPLOSIVE UPPER LIMIT

\begin{tabular}{|c|c|c|c|c|c|c|}
\hline Resource & SS & df & MS & F & $\begin{array}{c}\mathrm{P}- \\
\text { value }\end{array}$ & $\begin{array}{c}\text { conclusio } \\
n\end{array}$ \\
\hline $\begin{array}{l}\text { ignition } \\
\text { energy }\end{array}$ & 0.830225 & 3 & 0.276742 & 881.6549 & $\begin{array}{c}1.99 \mathrm{E} \\
-11\end{array}$ & $\begin{array}{l}\text { extremely } \\
\text { significant }\end{array}$ \\
\hline $\begin{array}{c}\text { initial } \\
\text { temperature }\end{array}$ & 0.180725 & 3 & 0.060242 & 191.9204 & $\begin{array}{c}1.79 \mathrm{E} \\
-08\end{array}$ & $\begin{array}{l}\text { extremely } \\
\text { significant }\end{array}$ \\
\hline error & 0.002825 & 9 & 0.000314 & & & \\
\hline total & 1.013775 & 15 & & & & \\
\hline
\end{tabular}

TABLE XII. TWO-FACTOR VARIANCE ANALYSIS ON EXPLOSIVE LOWER LIMIT

As can be seen from the data in Table 11and Table 12, under the coupling condition of the initial temperature and ignition energy, both initial temperature and ignition energy have extremely significant effects on the upper and lower limits of the gas explosion. 


\section{CONCLUSION}

(1) It is obtained that the variation of the upper and lower limits of gas explosion under the influence of initial temperature, ignition energy and the coupling condition of those two factors.

(2) The coupling condition of initial temperature and ignition energy has a great influence on the gas explosive limit. With the increase of initial temperature and ignition energy, the upper limit of gas explosion increases and the lower explosive limit decreases, and its rising and falling trends tend to be gentle.

(3) Under the coupling condition of initial temperature and ignition energy, both those two factors have extremely significant effects on the upper and lower limits of the gas explosion.

\section{ACKNOWLEDGMENT}

In this paper, the research was sponsored bythe National Key Research and Development Program of China (2016YFC0801703, 2017YFC0805207), the Key Research and Development Program of Shandong Province ( 2018GSF120016 , 2018GGX109004 ), the Nature Science of Shandong Province (ZR2015PE005) and Shandong University of Science and Technology Scientific Research Fund Project of Talent Introduction (2015RCJJ038).

\section{REFERENCES}

[1] Wang Derming. Thermodynamic Disaster in Coal and Its Characteristics [J].Journal of China Coal Society,2018,43(01):137142.

[2] Wang Guodong, Yang Xiutie. Research on Technical Reasons and Countermeasures of Coal Gas Explosion Accidents in Recent Years [J]. Safety in Coal Mines2018,49(01):230-232+236.

[3] Liu Rulin, Yu Yanbin. Analysis of Coal Mine Gas Explosion Accidents Based on FTA-AHP Method[J]. Journal of Shandong University of Science and Technology (Natural Science),2017,36(06):81-89.

[4] Zhang Jinjia, Xu Kaili, Wang Yantong, et al. Study on Causation Mechanism of Extraordinary Serious Gas Explosion Accidents in Coal Mines [J]. China Safety Science Journal,2017,27(01):48-52.

[5] Fan Baolong. Study on the Characteristics of Methane-Air \& Coal Dust-Air Mixing Process and Explosion in Large Scale Conditions [D]. Beijing Institute of Technology,2015.

[6] Xie Yiyue,Tan Yingxin ,Sun Yanlong. Explosive limits of methane in turbulent flow [J]. China Safety Science Journal,2016,26(11):65-69.

[7] Gao Zhichong, Zhao Ping. Influence of Initial Temperature on Gas Explosive Limits[J]. Journal of Taishan University,2015,37(06):76-79.

[8] Caron M, Goethals M,De Smedt G, etal. Pressure dependence of the auto-ignition temperature of methane/air mixtures[J].Journal of Hazardous Material,1999,65(3):233-244.

[9] Xu Chunzhao, Si Rongjun, Li Runzhi. Study on Change Laws of Gas Explosion Limits Under Extremely High Temperature Conditions [J]. Safety in Coal Mines,2015,46(04):1-4.

[10] [10] Gao Na, Zhang Yansong, Hu Yiting. Study on the Influence of Temperature and Pressure on the Methane-air Mixture Explosive Limits [J]. Explosion and Shock Waves,2017,37(03):453-458.

[11] Meng Guangshi. Selection of Factors Affecting Gas Explosion in Coal Mines and Establishment of Analytical Models [J]. Mining Safety \& Environmental Protection, 2004, (2):15-17.
[12] L. Dupont, A. Accorsi. Explosion characteristics of synthesized biogas at various temperatures [J]. Journal of Hazardous Materials, Volume 136, Issue 3, 25 August 2006, Pages 520-525.

[13] Li Runzhi. Study of the Influence of Ignition Energy and Initial Pressure on the Ga Explosion [D]. Shandong University of Science and Technology,2010.

[14] Koshiba, Y., et al. (2017). "Flammability limits, explosion pressures, and applicability of Le Chatelier's rule to binary alkane-nitrous oxide mixtures." J Loss Prevent Proc (1.409) 45: 1-8.

[15] Jin Yongfei, Song Yue, Chang Fangming. Influence of Ignition Energy on Methane Explosion Limit Under Pulse Ignition Way [J]. College of Safety Science and Engineering,2017,48(10):28-30.

[16] Zhu Peikai, Influence of Environmental Factors on Limit Concentration of Methane and Explosive Characteristics [D]. Shandong University of Science and Technology,2017.

[17] Zhang Guang, Tong Mingming, Ren Zihui. Experimental Studies on Effect of Alkane Gases on Lower Explosion Limits of Methane[J]. Journal of Kunming University of Science and Technology (Natural Science Edition),2011,(2):6-9.

[18] Wei Yongsheng, Zhou Bangzhi, Zheng Minyan. Analysis of Multiple Regression on the Explosive Limits of the Mixture of $\mathrm{H} 2 、 \mathrm{CO}$ and CH4 [J]. Chemical Research and Application,2004,16(3):419-424.

[19] Wang Ying. Experimental Study of the Characteristic of Gas Explosion in $20 \mathrm{~L}$ Spherical Hermetic Device [D]. North University of China,2012.

[20] Wang Tao. Experimental and Numerical Studies on Methane Explosion and the Suppression Effect of $\mathrm{CO} 2$ in Vessel[D]. Xi'an University of Science and Technology,2014.

[21] T.K.Subramaniam, Joseph V.Cangeiosi. Predicting Safe Oxygen Concentration in Flammable Gases [J]. Low Temperature and Specialty Gases, 1992, (2):49-55.

[22] Bolk J W, Siccama N B, Westerterp K R. Flammability limits in flowing ethane-air-nitrogen mixtures: An experimental study[J]. Chemical Engineering science, 1996, 51(10): 2231-2239

[23] Gao Na. Study on Influence of Initial Temperature and Pressure on Gas Explosion Characteristics[D]. Nanjing University of Science and Technology,2016.

[24] Zhang Yinhe, Zhang Yansong, Ren Jianxi. Study on the Effect of Coal Dust on Low Concentration Gas Explosion [J]. Mining Safety \& Environmental Protection,2006,6(33):20-21.

[25] Si Rongjun, Wang Chunqiu. Experimental Research on the Influence of Gas on the Character of Coal Dust Explosion [J]. China Safety Science Journal,2006,16(12):86-91.

[26] Addai, E. K., et al. (2015). "Lower explosion limit of hybrid mixtures of burnable gas and dust." J Loss Prevent Proc (1.409) 36: 499-506.

[27] Fen Yongan. Experimental Study of Methane Effects on Coal Dust Explosion in 201 Spherical Hermetic Divice[D]. North University of China,2013.

[28] Li Zheng. Experimental Study of Gas Explosion and Its Suppression with Water Mist[D]. Dalian University of Technology,2011.

[29] Qu Zhongwei. Research on Flammability Limit and Quenching Mechanism of Flame of Premixed Methane Gas [D]. AnHui University of Science and Technology,2016.

[30] Wei Cunjuan. Research of Explosion Process on Premix Gas of Methane-Air in Horizontal Pipeline[D]. North University of China,2010.

[31] Si Rongjun. Experimental Study on the Influence of Temperature Coupled with Pressure on the Gas Explosive Limits[J]. Journal of Safety and Environment,2014,14(04):32-35.

[32] Van den Schoor, F. and F. Verplaetsen (2006). "The upper explosion limit of lower alkanes and alkenes in air at elevated pressures and temperatures." J Hazard Mater (4.836) 128(1): 1-9.

[33] Meng Xiangbao. Experiment and Simulation Study on the Influence of Ignition Energy and Initial Temperature on the Gas Explosion [D]. Shandong University of Science and Technology,2014.

[34] Cao Juzheng, Ma Xiang, Wang Zhengang, Wang Ben, Xie Chuanxin. Analysis of Commonly- seen Alkenes Explosive Characteristics [J]. Industrial Safety and Environmental Protection,2013,39(05):67-69 